\title{
Pre- and intraoperative mitomycin $C$ for recurrent pterygium associated with symblepharon
}

This article was published in the following Dove Press journal:

Clinical Ophthalmology

22 January 2013

Number of times this article has been viewed

\section{Isyaku Mohammed}

Department of Ophthalmology, Aminu Kano Teaching Hospital, Kano, Nigeria
Correspondence: Isyaku Mohammed Department of Ophthalmology, Aminu Kano Teaching Hospital, PMB 3452,

Kano, Nigeria

Tel +234803604 7607

Email akthkano@yahoo.com
Background: Treatment of recurrent pterygium associated with symblepharon usually involves the use of tissue grafting and/or the intraoperative application of mitomycin $\mathrm{C}$ (MMC). For the graft, a conjunctival/limbal autograft and/or amniotic membrane may be used. This generally requires extra technical skills and assistance, an increase in the cost and duration of surgery, and a more extensive anesthesia (a complete eye block or general anesthesia). Although widely used, safety concerns have been raised over MMC in the treatment of pterygia.

Objective: The objective of this case report is to report the successful use of preoperative subconjunctival injection of low-dose (0.02\%) MMC one month before bare sclera excision of a multirecurrent pterygium, as well as the concomitant intraoperative application of MMC to the conjunctival fornix of the same eye after the excision of an associated symblepharon.

Case report: A 31-year-old man from Kano, Northern Nigeria, presented to the eye clinic with a recurrent pterygium associated with an upper lid symblepharon in his right eye. He has had five previous pterygium excisions, with the last surgery involving conjunctival autografting and subconjunctival steroid injection. He was subsequently given $0.1 \mathrm{~mL}$ of $0.02 \% \mathrm{MMC}$ as a subpterygial injection; one month later he had an alcohol-assisted bare sclera pterygium excision and a symblepharolysis with the intraoperative application of $0.02 \%$ MMC for 1 minute to the upper conjunctival fornix. Except for a Tenon granuloma that was simply excised, there has been no recurrence or other complications up to a year after surgery.

Conclusion: As a cheaper and technically easier treatment option, a preoperative subconjunctival MMC injection followed by bare sclera pterygium excision was found to be effective in this patient with a recurrent pterygium. As at one-year follow-up, low-dose preoperative MMC a month prior to surgery also appeared safe and effective when combined with its intraoperative application to the conjunctival fornix for the treatment of associated symblepharon.

Keywords: mitomycin C, pterygium, recurrence, symblepharon

\section{Introduction}

A pterygium is a wing-shaped fibrovascular conjunctival growth that advances onto the cornea. It is speculated to occur as a result of a failure of the limbal barrier caused by postulated environmental, genetic, and/or various other factors. ${ }^{1}$ The main challenge in the surgical management of pterygia is the issue of recurrence. To prevent this, various adjunctive treatments that include chemotherapy, radiotherapy, and surgical transplants have been employed. ${ }^{2}$ Adjuvant treatments have significantly reduced but not eliminated the problem; as for the recurrent pterygium, there are greater challenges associated with its treatment. Added to an increased recurrence rate is the problem of deciding on the best approach to its surgical excision, since a recurrent pterygium is usually associated with subconjunctival fibrosis and/or corneal thinning and scarring. 
There is no recommended best treatment approach for the recurrent pterygium. Single treatments or a combination of treatments that include tissue grafting and chemotherapeutic agents have been utilized with varying degrees of success as adjuncts to simple excision. ${ }^{3}$ The drug Mitomycin C (MMC) has vasculopathic and antifibrotic properties and has been mainly used after pterygium excision as an intraoperative application to the bare sclera for the management of both primary and recurrent pterygium. ${ }^{4}$ In order to further reduce recurrence and postoperative complications, an intraoperative MMC-treated sclera is normally covered with a conjunctival or amniotic membrane graft. ${ }^{5}$ The possibility of potentially serious complications associated with the use of MMC has necessitated its usage with caution. ${ }^{2,6}$ It is therefore not known to be used both pre- and intraoperatively on the same patient. This report is on the successful such use of low-dose MMC in a patient with recurrent pterygium associated with a symblepharon who had undergone five previous excisions.

\section{Case report}

A 31-year-old male outdoor salesman presented to the ophthalmology department of the Aminu Kano Teaching Hospital with a complaint of a recurrent growth on the right eyeball. He had had four previous excisions of the growth at two different hospitals over the previous five years, but with a recurrence less than six months after surgery on each occasion. The nature of the previous surgeries was not clear, but there was nothing suggestive of adjuvant use of chemo or radiotherapy. There was no history suggestive of systemic illness, blepharitis, allergy, or dry eye disease. On examination, he had a visual acuity of 6/9 OD and 6/6 OS that improved with refraction by one line for each eye. The eyelids were normal and there was a fleshy recurrent nasal pterygium on the right eye that extended to the edge of the pupil. Ophthalmoscopy revealed a normal fundus and there was no restriction of extraocular muscle motility. Using topical $0.5 \%$ tetracaine hydrochloride (Alcon-Couvreur, Puurs, Belgium) and subconjunctival 2\% lignocaine with 1:100,000 noradrenaline (Lignovit 20-AH, Vital Healthcare PVT Limited, Mumbai, India) local anesthesia, he subsequently underwent a simple pterygium excision (avulsion technique) followed by a free conjunctival autograft that was harvested from the superior bulbar conjunctiva and secured with $9 / 0$ nylon suture. He was then given a subconjunctival injection of $20 \mathrm{mg}$ methylprednisolone acetate (Depomedrol, Pfizer Limited, Mumbai, India) in the lower fornix. Histology confirmed a pterygium and, postoperatively, he was placed on 6-hourly topical $0.1 \%$ dexamethasone eye drops (Maxidex, Alcon-Couvreur, Puurs, Belgium) and 8-hourly $0.5 \%$ chloramphenicol eye drops (Elisca, Medreich, Bangalore, India) for four weeks and 50-mg oral diclofenac tablets (Clofenac, Hovid Berhad, Malaysia) twice daily for one week. Four months after this fifth excision, and while still on his now-12-hourly steroid eye drops, there was a pterygium recurrence that kept growing across the limbus and onto the cornea. This was later complicated by the formation of an upper lid symblepharon (Figure 1).

Three months after this fifth reoccurrence, the patient had a preoperative subpterygial injection of $0.1 \mathrm{~mL}$ of 0.02\% MMC (MMC Kyowa, Biochem Industries, Daman, India) in preparation for the sixth surgical procedure. A month after the MMC injection and under local anesthesia as in the fifth procedure, he underwent an excision of the symblepharon, including the surrounding subconjunctival fibrous tissue. MMC (0.02\%) was applied using a sponge to the deep upper conjunctival fornix for 1 minute, followed by copious saline irrigation. An ethanol (20\%)-assisted blunt pterygium excision was then done, leaving a bare untreated sclera. Postoperative medication was prescribed as in after the fifth excision. There were no intraoperative complications, and postoperative cosmesis was good after this sixth procedure. Two months later, the patient developed a small Tenon's granuloma that was simply excised and histologically confirmed. There have been no other complications or recurrence of pterygium since then, up to a year after the sixth procedure (Figure 2). There has been full extraocular muscle motility, and unaided visual acuity has remained unchanged.

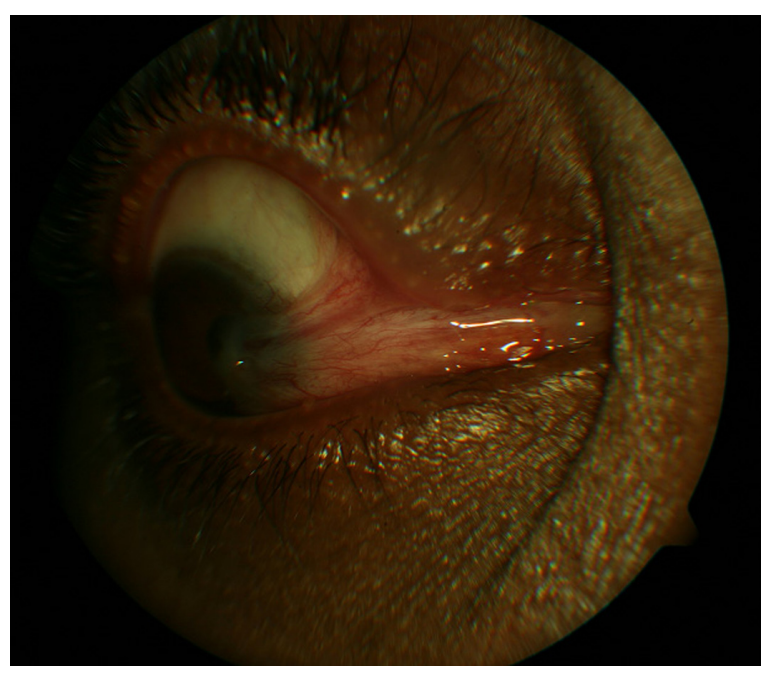

Figure I Multirecurrent pterygium (five previous excisions) with symblepharon before treatment. 


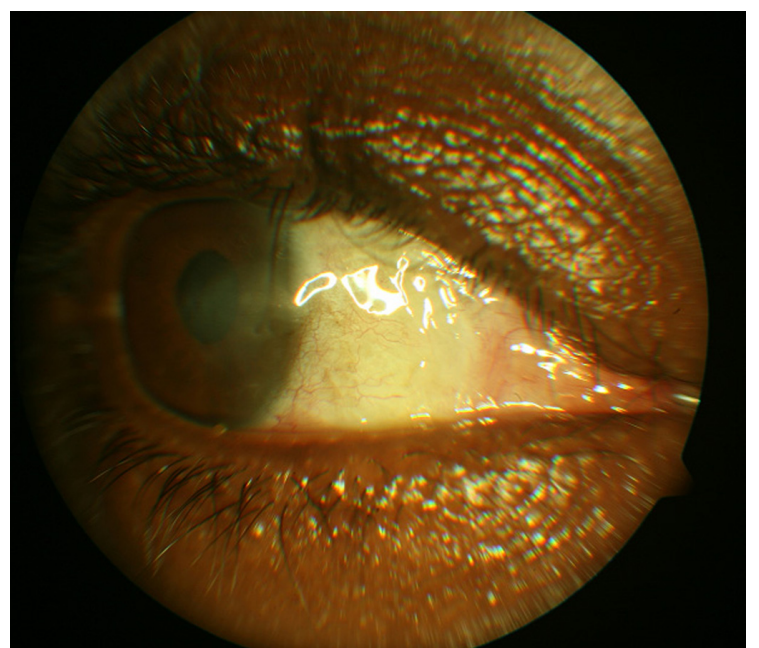

Figure $2 \mathrm{~A}$ year after bare sclera excision with adjunctive pre and intraoperative use of mitomycin C.

\section{Discussion}

Conjunctival or limbal autografts and amniotic membrane transplants have been commonly used alone or combined with MMC as adjuvant treatment for recurrent pterygium ${ }^{3}$ with fairly good results, whether there was an associated symblepharon or not. Perhaps the recently described method of extended pterygium removal followed by an extended and relatively large conjunctival graft seems to be the most promising treatment that tends toward a zero-recurrence rate. ${ }^{7}$ This should probably be the recommended treatment of choice for recurrent pterygia, even though it has some drawbacks. These drawbacks include the requirement for a more extensive or general anesthesia, a longer operating time of about 2 hours, the need for a skilled assistant, poor immediate postoperative cosmesis, and a relatively prolonged postoperative diplopia and pain. $\mathrm{MMC}$ in the treatment of recurrent pterygia has been more commonly used as an intraoperative topical application. ${ }^{2,8}$ Preoperative subconjunctival injections of MMC are usually given from a day up to a month prior to surgery, and intraoperative tissue grafting to cover the bare sclera after pterygium excision is usually not necessary. ${ }^{9}$ This mode of use makes it technically easier compared to other methods that involve tissue grafting and, in comparison to intraoperative MMC, allows for exact dose titration to the intended site, thereby increasing its effectiveness in preventing pterygium recurrence. This may, however, increase the risk for complications, as was reported by Carrasco et al, ${ }^{10}$ where a 55 -year-old man with preexisting dry eye disease developed scleral ulceration after a preoperative injection of $0.15 \mathrm{~mL}$ of low-dose MMC. Adjuvant MMC treatment in all cases must of course only be used in patients with no contraindications to its use, such as dry eye disease and conditions that predispose to poor wound healing. When there is an associated symblepharon, preoperative subpterygial MMC and the later intraoperative use of MMC to the conjunctival fornix may carry fewer worries about toxicity compared to simultaneous intraoperative application of MMC to the sclera and fornix. In this patient, the same low-dose MMC was applied to the deep upper conjunctival fornix for 1 minute before saline irrigation. A higher MMC dose (up to $0.04 \%$ ) or longer application period (commonly 3 to 5 minutes ) was not used for this patient in order to reduce the risk of postoperative MMC-related complications. Costs and surgical time are reduced when items like amniotic membrane and suture/tissue glue are not used. The added cost and non-availability of these items at the time of surgery was the main reason for the choice of using preoperative MMC over other options in this patient. Although subconjunctival/subpterygial injections could be slightly more difficult to give for recurrent pterygia (due to subconjunctival scarring and fibrosis), that is less of a task compared to harvesting conjunctiva for grafting on an eye that had possibly undergone a previous graft, as is the case with this patient. Some surgeons prefer preoperative MMC a week or even a day prior to surgery. Timing differences may not be important, but shorter times may presumably lead to a higher incidence of postoperative complications such as delayed corneal epithelial healing and scleral thinning/ avascularity. This is, however, subject to confirmation by large-sample comparative studies. However, in a study by Zaky and Khalifa ${ }^{11}$ where subconjunctival low-dose MMC was given a day prior to surgery, out of a total of 25 eyes with recurrent pterygia, two had postoperative delayed epithelization. For this patient, prior MMC injection a month instead of a day or few days prior to surgery was preferred because of the intended intraoperative MMC fornix application. Other possible but relatively minor complications associated with the use of MMC include superficial punctuate keratitis, corneal edema, scleritis, scleral dellen, and pyogenic granuloma. ${ }^{12}$ In view of its radiomimetic properties, MMC also has the potential for long-term complications that could include uveitis, cataract, glaucoma, endophthalmitis, and scleral melting leading to globe perforation., ${ }^{2,13}$ Therefore, there is a need for long-term follow-up of the patient discussed in this case report.

\section{Conclusion}

This case would generally seem to suggest that, in some selected patients with recurrent pterygium associated 
with a symblepharon, the combined use of preoperative subconjunctival low dose MMC injections up to a month prior to pterygium excision, along with its intraoperative conjunctival fornix application after symblepharolysis, could serve as an effective and technically easier adjuvant treatment option. Larger cohort studies and postoperative monitoring over much longer time periods will, however, be needed in order to fully evaluate treatment safety profile.

\section{Disclosure}

The author declares no conflict of interest in this work.

\section{References}

1. Detorakis ET, Spandidos DA. Pathogenetic mechanisms and treatment options for ophthalmic pterygium: Trends and perspectives (Review). Int J Molecular Med. 2009;23:439-447.

2. Mohammed I. Treatment of pterygium. Ann Afr Med. 2011;10:197-203.

3. Shimazaki J, Shinozaki N, Tsubota K. Transplantation of amniotic membrane and limbal autograft for patients with recurrent pterygium associated with symblepharon. Br J Ophthalmol. 1998;82:235-240.

4. Ang LP, Chua JL, Tan DT. Current concepts and techniques in pterygium treatment. Curr Opin Ophthalmol. 2007;18:308-313.
5. Katircioglu YA, Altiparmak UE, Duman S. Comparison of three methods for the treatment of pterygium: amniotic membrane graft, conjunctival autograft, and autograft plus mitomycin C. Orbit. 2007;26:5-13.

6. Rubinfeld RS, Pfister RR, Stein RM, et al. Serious complications of topical mitomycin C after pterygium surgery. Ophthalmology. 1992;99: $1647-1654$

7. Hirst LW. Recurrent pterygium surgery using pterygium extended removal followed by extended conjunctival transplant: recurrence rate and cosmesis. Ophthalmology. 2009;116:1278-1286.

8. Shehadeh-Mashor R, Srinivasan S, Boimer C, Lee K, Tomkins O, Slomovic AR. Management of recurrent pterygium with intraoperative mitomycin $\mathrm{C}$ and conjunctival autograft with fibrin glue. $A m J$ Ophthalmol. 2011;152:730-732.

9. Donnenfeld ED, Perry HD, Fromer S, Doshi S, Solomon R, Biser S. Subconjunctival mitomycin $\mathrm{C}$ as adjunctive therapy before pterygium excision. Ophthalmology. 2003;110:1012-1016.

10. Carrasco MA, Rapuano CJ, Cohen EJ, Laibson PR. Scleral ulceration after preoperative injection of mitomycin $\mathrm{C}$ in the pterygium head. Arch Ophthalmol. 2002;120:1585-1586.

11. Zaky KS, Khalifa YM. Efficacy of preoperative injection versus intraoperative application of mitomycin in recurrent pterygium surgery. Indian J Ophthalmol. 2012;60:273-276.

12. Cheng HC, Tseng SH, Kao PL, Chen FK. Low dose intraoperative mitomycin C as chemoadjuvant for pterygium surgery. Cornea. 2001;20: 24-29.

13. Safianik B, Ben-Zion I, Garzozi HJ. Serious corneoscleral complications after pterygium excision with mitomycin C. Br J Ophthalmol. 2002;86: $357-358$.
Clinical Ophthalmology

\section{Publish your work in this journal}

Clinical Ophthalmology is an international, peer-reviewed journal covering all subspecialties within ophthalmology. Key topics include: Optometry; Visual science; Pharmacology and drug therapy in eye diseases; Basic Sciences; Primary and Secondary eye care; Patient Safety and Quality of Care Improvements. This journal is indexed on

\section{Dovepress}

PubMed Central and CAS, and is the official journal of The Society of Clinical Ophthalmology (SCO). The manuscript management system is completely online and includes a very quick and fair peer-review system, which is all easy to use. Visit http://www.dovepress.com/ testimonials.php to read real quotes from published authors. 